\title{
Reseña: Una historia de la psicología educativa peruana
}

A history of educational psychology at Peru

Recibido: diciembre 15 de 2013 | Revisado: junio 9 de 2014 | Aceptado: julio 17 de 2014

TOMÁs CAYCHO RodRÍGUEZ*

Universidad Inca Garcilaso de la Vega, Lima, Perú

doi:10.11144/Javeriana.upsy13-5.hpep

Para citar este artículo: Caycho, T. (2014). Una historia de la psicología educativa peruana [Reseña del libro Documentos para una historia de la psicología educacional en el Perú]. Universitas Psychologica, 13(5), 1755-1757. http://dx.doi.org/10.11144/Javeriana.upsy13-5.hpep

* Correo electrónico: tcaycho@uigv.edu.pe
Salas y Lizama (2013) señalan que "la historia de la psicología debe ocuparse de los factores internos de la psicología y de las fuerzas externas que condicionan la actividad científica, ya sean políticas, económicas, socioculturales, etc., con la finalidad de contribuir a la conservación de la historia de la profesión" (p. 39). Esta definición es acorde con el objetivo del libro de los destacados psicólogos peruanos, Anibal Meza Borja y Carmen Lazarte Torriani, Documentos para una historia de la psicología educacional en el Perú, editado en Lima en 2010 por Editorial Universitaria. Los autores señalan que su libro tiene como propósito "brindar una imagen de lo que ha sido la psicología educacional, en general, y la investigación psicoeducacional, en particular, en el Perú" (p. 9). En el Perú, obras sobre historia de la psicología peruana y su desarrollo son escasas. A la tradición iniciada por Reynaldo Alarcón $(1969,2000)$ y Ramón León $(1993)$, en los últimos años, le han seguido nuevos trabajos referidos tanto al desarrollo histórico de la psicología en el Perú (Arias, 2010) como a los psicólogos peruanos (Caycho, 2012, 2013a, 2013b). Con respecto a la historia de la psicología educativa, ya en 1961, Alarcón publica un artículo acerca del desarrollo de la psicopedagogía en el Perú (Alarcón, 1961) y, en años recientes, Merino, Díaz, Zapata y Benites (2006) publican una revisión histórica de la psicología educativa.

El libro reúne dos trabajos de los autores, publicados a fines de 1980 e inicios de la década de 1990, así que se describe y analiza el devenir de la psicología educativa en el Perú desde sus inicios hasta 1990. El primer capítulo, titulado "Panorama de la psicología educacional en el Perú”, se revisan los orígenes 
y desarrollo de la psicología educativa. Coincidiendo con Alarcón (1969), los autores establecen dos periodos claramente diferenciados. El primero caracterizado por la labor de los pioneros no psicólogos, sino médicos o educadores, quienes realizaban contribuciones individuales y esporádicas de investigación psicoeducativa. El segundo periodo tiene como puntos más notorios la institucionalización, la sistematización y la rigurosidad de la investigación, sobresaliendo la figura del dr. Walter Blumenfeld, considerado como el fundador de la psicopedagogía peruana (Tapia, 2005). En seguida, el capítulo revisa la labor de los psicólogos escolares y educativos en diferentes actividades como la orientación y bienestar del estudiante, la educación especial, la estimulación temprana, la investigación básica y aplicada, así como la producción de libros, pruebas psicológicas y otros. Finaliza con un balance de lo logrado por la psicología educativa hasta esa época, con algunas sugerencias para su desarrollo futuro. El segundo capítulo, "Análisis, diagnóstico y perspectivas de la investigación psicoeducacional en el Perú”, es un estudio donde se analiza la producción en investigación psicoeducativa realizado por el, ya desaparecido, Instituto Nacional de Investigación y Desarrollo Educativo (INIDE), así como por las universidades.

Como observará el lector, la obra se trata de una verdadera exposición de la psicología educativa hasta 1990, en la que casi todos los aspectos de la misma reciben atención. La obra posee un enorme valor, ya que ofrece conclusiones importantes para la reflexión acerca de la investigación en la psicología educativa peruana actual y lo que se podría esperar en un futuro, entre las que destacan la no existencia de una política definida respecto a los temas prioritarios en investigación psicoeducativa, el reclutamiento y desarrollo de recursos humanos, materiales y económicos, así como lo relacionado con la comunicación y difusión de los resultados de las investigaciones. Algunas sugerencias importantes que se desprenden del texto son la posibilidad de crear un Archivo Nacional de Investigación en Psicología Educativa y la divulgación de los resultados de investigaciones psicoeducativas en revistas y medios de difusión más amplios, buscando también una mayor presencia del psicólogo educativo en el debate nacional sobre temas de interés público.

Como ocurre con muchos trabajos históricos, la revisión suele ser parcial e incompleta; en este caso, el libro se ha circunscrito a la producción de investigaciones psicoeducativas aparecida en Lima, dejando de lado investigaciones realizadas en otras ciudades del Perú. Del texto se desprenden también algunas interrogantes; una de ellas es: iqué significado tiene la obra? Aquí se visualiza el crecimiento de la psicología educativa y el valioso aporte de los psicólogos a temas de interés nacional, como los aportes de Raúl Gonzales Moreyra al estudio de los aspectos psicológicos asociados al bilingüismo. La obra es importante para todos los psicólogos peruanos, pero también es de suma utilidad para los historiadores de la psicología, quienes leerán con especial placer un trabajo como este, con multitud de datos acerca de la psicología en el Perú.

Meza y Lazarte han aportado, con este trabajo, una valiosa contribución a la literatura psicológica peruana, de gran utilidad tanto para el estudiante como para el catedrático e investigador universitario. La obra no es una simple adición a la lista de textos sobre historia de la psicología, sino una expresión de la vitalidad y desarrollo de la misma como especialidad en el Perú, que no es más sino resultado del desarrollo de la psicología en este país, que hace necesaria una reflexión acerca del pasado de nuestra ciencia en busca del significado de nuestra propia identidad.

\section{Referencias}

Alarcón, R. (1969). Panorama de la psicopedagogía en el Perú. Serie Monografías Psicopedagógicas N.ㄴ 2 . Lima, Perú: Instituto Psicopedagógico Nacional.

Alarcón, R. (2000). Historia de la psicología en el Perú. De la Colonia a la República. Lima: Editorial Universitaria.

Arias, W. (2010). Desarrollo de la historia de la psicología en el Perú. Revista Peruana de Psicología, 9(1), 101-109.

Caycho, T. (2012). La contribución psicológica de Federico R. León al desarrollo de la psicología peruana 
y latinoamericana. Revista de Psicología de Arequipa, 2(2), 142-163.

Caycho, T. (2013a). Aproximación a la obra psicológica de Reynaldo Alarcón y su contribución a la psicología científica en el Perú. Revista de Historia de la Psicología, 34(3), 7-24.

Caycho, T. (2013b). Walter Blumenfeld: vida y obra de un pionero en el desarrollo de la psicología científica en el Perú. Eureka, 10(2), 216-229.

Merino, C., Díaz, M., Zapata, L., \& Benites, L. (2006). School psychology in Peru. En S. R. Jimerson, T.
O. Oakland \& P. T. Farell (Eds.), The handbook international of school psychology (pp. 299-307). Oakland: Sage.

Salas, G., \& Lizama, E. (2013). Historia de la psicología en Chile, 1889-1981 (2.a ed.). La Serena: Editorial Universidad de la Serena.

Tapia, V. (2005). La psicopedagogía en el Perú. En H. Sánchez \& C. Reyes (Eds.), Temas de psicopedagogía (Vol. 1, pp. 13-17). Lima: Visión Universitaria. 
